\title{
OBSERVATIONS ON TUBERCULOUS MENINGITIS *
}

\author{
BY \\ JAMES MCMURRAY, M.D. \\ (From the Institute of Pathology, Queen's University, Belfast)
}

There are two aspects of tuberculous meningitis which are worthy of discussion. One is its mode of development. Why, for instance, does it not arise in every case of tuberculous bacillaemia? The other aspect is the frequency with which the bovine type of tubercle bacillus occurs in tuberculous meningitis. Both these are well known to a few but not appreciated by many. In this paper investigations have been made of both these aspects of tuberculous meningitis.

\section{Pathogenesis}

From the pathological side attempts have been made to determine the origin and development of the disease process in tuberculous meningitis. There are two schools of thought. Some think it arises as the result of a spread of tubercle bacilli from a parent focus into the subarachnoid space. The initial lesion might either be in the meninges or juxta-meningeal tissues of brain or cord. This idea was first sponsored by Rich and McCordock (1933) and later supported by Macgregor and Green (1937). The previous contention was that the meningitis was nearly always the direct result of a tuberculous bacillaemia and occurred therefore simultaneously with other haematogenous foci. In other words miliary tuberculous lesions in other organs coincided with the meningitis and were the same age. This conception was maintained by some workers such as Ragins (1936) and Radmann (1935) as being the way in which the majority of cases of tuberculous meningitis developed.

Rich and others (1933) have experimentally investigated the problem. They attempted to produce the meningitis in animals. The injection of tubercle bacilli into the carotid artery did not cause a rapid development of tuberculous meningitis. In a few cases, however, the meningitis did develop, but always after a lapse of some weeks. Post-mortem examination revealed the presence of miliary tubercles in the brain and elsewhere in the body and also that the meningitic lesion was more recent than those tuberculous lesions elsewhere in the body. The injection of tubercle bacilli into the subarachnoid space, however, promptly resulted in the development of tuberculous meningitis. These results strongly support the opinion that tuberculous meningitis does not arise directly from a bacillaemia

* Based on a thesis for which the Davis Scholarship of the Belfast Hospital for Sick Children was awarded. but indirectly as the result of the extension of a haematogenous focus.

In this work a detailed examination of the brains of eleven cases was made. In each case an attempt was made to determine whether or not the following were true:

(1) A parent meningeal focus or juxta meningeal focus existed and was extending into the subarachnoid space to produce a meningitis.

(2) When miliary lesions did occur they were of different age from the meningeal lesions.

(3) The exudate spread from the parent focus and collected around the base of the brain.

(4) The choroid was normal and the ventricular ependyma was unaffected.

Technique. When possible a complete postmortem examination was made in each case. Removal of spinal cord was not possible. The brain was fixed and later serially sectioned in slices $1-2 \mathrm{~mm}$. thick. Careful search was made for tuberculous nodules in the meninges or in the brain. The meninges covering the brain and in the sulci were carefully examined. The cut surface of the brain was scrutinized for foci deep in the substance or near the surface and encroaching on the meninges. Both the definite and the doubtful foci were examined histologically. Some of the standard criteria used were as follows.

A parent focus was recognized as such because of its size or of its position relative to the meningitis. Large foci left no doubt. It was more difficult to be sure of small foci in the superficial brain or in the meninges. In these the tissue reaction was the guide. A nearby gliosis in some cases and in others a surrounding zone of very extensive cellular exudate with much necrosis and arteritis was regarded as evidence in favour of its being the exciting focus. Determination of the relative ages of the foci in the brain and of the meningitis was based mainly on the size and cellular character of the lesion. In cases in which the meningitis was thought to be older than the miliary foci the meninges showed a thick exudate, not much necrosis and arteritis and some meningo-encephalitis. The cerebral lesions showed very little perifocal gliosis. If the meningitis was regarded as the more recent, the haematogenous foci were well formed and showed a more marked glial reaction around them. The meningeal exudate was scanty but more necrotic and showed less compact cellular infiltration. 


\section{Results of investigation}

Parent foci: meningeal or juxta meningeal. Eleven brains were examined and two were found to have localized foci in brain substance (table 1). One case had a localized lesion in the cerebellum which apparently had provoked a meningeal exudate. The other case had two foci, one in left parietofrontal and the other in the cerebellum. The latter focus had become walled off by adhesion to the dura mater. The parietal focus was surrounded by a thick plaque of meningeal exudate. Eight other cases showed meningeal foci, very often in a sulcus and frequently near a main cerebral artery. These were distinguished from a basal condensation of exudate by the fact that they did not occur symmetrically. In one case a precipitating focus was not found inside the skull. In this case (No. 11) miliary lesions appeared older than the meningeal exudate. Thus ten out of eleven cases showed a precipitating focus inside the skull.

Miliary tuberculosis. Miliary tuberculosis occurred in five cases out of the eleven. In one of these

TABLE 1

\begin{tabular}{|c|c|c|c|c|c|c|c|}
\hline No. & Sex & $\begin{array}{l}\text { Age, } \\
\text { years }\end{array}$ & $\begin{array}{l}\text { Primary } \\
\text { complex }\end{array}$ & Parent focus & Miliary lesions & $\begin{array}{c}\text { Age of } \\
\text { meningitis to } \\
\text { miliary lesions }\end{array}$ & Other foci \\
\hline 1 & F. & 1 & R.U.L. & Meninges: right & None & - & Hilar glands \\
\hline 2 & M. & 17 & Not found & $\begin{array}{l}\text { Meninges: right } \\
\text { sylvian }\end{array}$ & None & - & None found \\
\hline 5 & M. & 5 & Not found & Cerebellum & None & - & None found \\
\hline 6 & M. & 2 & R.U.L. & $\begin{array}{l}\text { Meningeal: near } \\
\text { left middle } \\
\text { cerebral artery }\end{array}$ & None & - & In spleen \\
\hline 7 & F. & 4 & R.U.L. & $\begin{array}{l}\text { Meningeal: cere- } \\
\text { bellar peduncle }\end{array}$ & $\begin{array}{l}\text { In spleen and } \\
\text { lungs }\end{array}$ & Older & - \\
\hline 8 & M. & 17 & L.U.L. & $\begin{array}{l}\text { Meningeal: left } \\
\text { crus }\end{array}$ & None & - & $\begin{array}{l}\text { Intercostal and } \\
\text { prostate }\end{array}$ \\
\hline 9 & M. & $\frac{1}{2}$ & R.U.L. & $\begin{array}{l}\text { Meningeal: right } \\
\text { middle cerebral }\end{array}$ & $\begin{array}{l}\text { Spleen, lymph } \\
\text { glands, lungs, } \\
\text { liver and kidneys }\end{array}$ & Older & - \\
\hline 10 & M. & $1 \frac{1}{2}$ & R.U.L. & $\begin{array}{l}\text { Meningeal: right } \\
\text { middle cerebral }\end{array}$ & Spleen and liver & Younger & $\begin{array}{l}\text { Cerevical lymph } \\
\text { glands, right tonsil } \\
\text { and mesenteric glands }\end{array}$ \\
\hline 11 & M. & 2 & Mesenteric & Meningeal: ? & $\begin{array}{l}\text { Spleen, liver and } \\
\text { lungs }\end{array}$ & Younger & Old lesion in spleen \\
\hline 12 & M. & 10 & Pulmonary & $\begin{array}{l}\text { Left parieto- } \\
\text { frontal }\end{array}$ & Spleen, liver, lungs & Younger & Left cerebellum \\
\hline 14 & F. & $1 \frac{1}{2}$ & R.U.L. & $\begin{array}{l}\text { Meningeal: left } \\
\text { middle cerebral } \\
\text { artery }\end{array}$ & None & - & $\begin{array}{l}\text { Hilar and mesenteric } \\
\text { glands }\end{array}$ \\
\hline
\end{tabular}
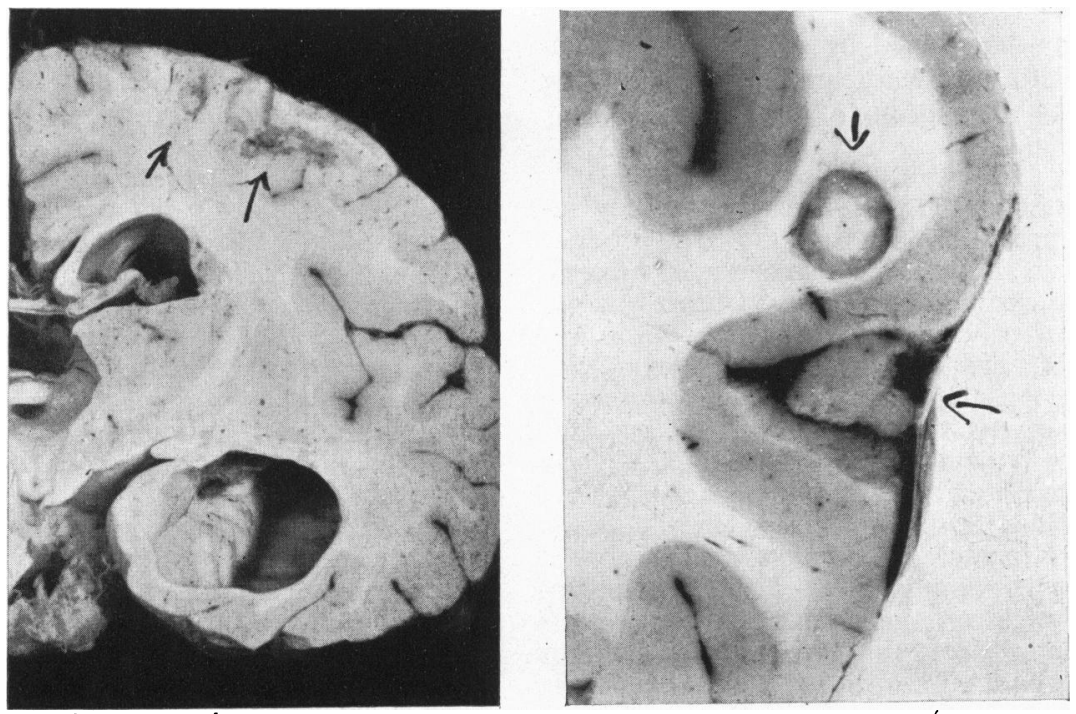

Fig. 1.-Cerebral foci involving meninges, basal meningitic exudate, slight hydrocephalus, Case 12 (A2926). 
cases a precipitating focus was found in the left parieto-frontal area. This focus was the same age as the other miliary lesions in the brain, lungs, liver and spleen. The age of this focus was therefore older than the meningitis. Three of the other four cases of meningitis with miliary tubercles showed parent foci in the meninges. In two of these cases the meningitis appeared to have occurred prior to the miliary spread. The other two cases had miliary lesions which appeared to have occurred after the meningitis. Thus in all five cases the age of the miliary lesions was different from that of the meningitis. Six other cases showed no evidence of miliary tuberculosis.

The meningeal exudate in all cases showed a basal condensation of varied degree. However, in some cases the exudate thickened around the parent foci. This was well marked in those two with large cerebral juxtameningeal foci. In others with small precipitating foci in the meninges this was not so apparent to the naked eye, but nevertheless was obvious in the histology (fig. 1 and 2).

The character of the exudate varied slightly in every case. In some, especially in the more recent, there was an exudate consisting of about equal numbers of mononuclear cells and polymorphs with some areas of necrosis and periarteritis. In other, longer established cases the exudate usually showed more mononuclears and also more necrosis and arteritis. This involvement of blood vessels in some cases was very extensive. In one case (not included in this series) a small tuberculous lesion was seen in the wall of a vein. This would support the contention that miliary tuberculosis can be the result of vascular involvement in a meningeal exudate.

Choroid plexus. None of the brains showed evidence of tuberculosis in the choroid plexus. There was no evidence of tuberculous involvement of the ependyma of the lateral and third ventricles or of the aqueduct of sylvius. In one case the ependyma showed involvement in the fourth ventricle. This was maximum near the foramina of Luschka and Magendie and diminished towards the Sylvian aqueduct. It was associated with a very thick exudate around the base and cerebellar peduncles.

\section{SUMMARY OF FINDINGS}

Tuberculous meningitis, total sectioned 11 cases Meningitis older than miliary lesions .. 2 ," Meningitis younger than miliary lesions 3 ,, Meningitis without miliary lesions .. 6 ", Meningitis with cerebral foci .. $\quad . .2$,"

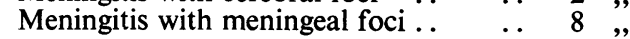

\section{Discussion}

Now if tuberculous meningitis is the result of a tuberculous bacillaemia miliary tuberculosis should occur in every case. In this series only five out of eleven cases also had miliary tuberculosis. Furthermore, the miliary tuberculous lesions should present the same age characteristics as the meningitis lesion. But in none of the cases did such happen. In two cases the meningitic exudate appeared more long standing than the miliary foci and in three it seemed more recent in origin. Therefore miliary tuberculosis was not always coexistent with tuberculous meningitis and when it was the lesions of each were found to be of different ages.

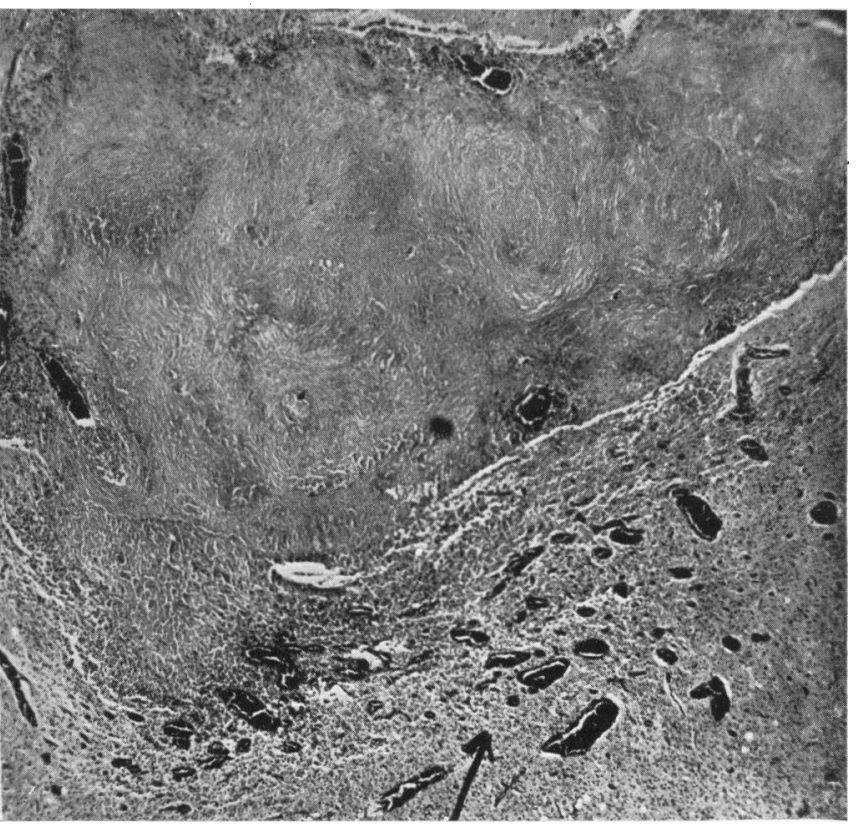

FIG. 2.-Meningeal focus involving brain producing local meningo-encephalitis.

The character of the exudate in all cases was the same. There was in all cases an apparent collection of exudate at the base of the brain around the basal vessels of the circle of Willis and the optic chiasma. In those cases with fairly large foci it was evident to the naked eye that the exudate was more marked around the foci than at the base. No cases showed any diffuse spread of exudate over the vertex as might be expected in a bacillaemic type of meningitis. Histologically too, if such were the usual mode of origin the vessels themselves would show evidence of multiple tuberculous thrombi as they would be involved in the inflammatory process and show a cellular infiltration of decreasing intensity from within out. This is not the usual finding in these cases examined. Instead, the common finding was that the maximum involvement of the wall of the small arteries was in the adventitia to a less extent in the media and usually slight in the intima (fig. 3).

Another suggested possibility as to the pathogenesis is that bacilli passed through vascular endothelium in the choroid plexus into the cerebrospinal fluid. In those cases no evidence was found to support this. 


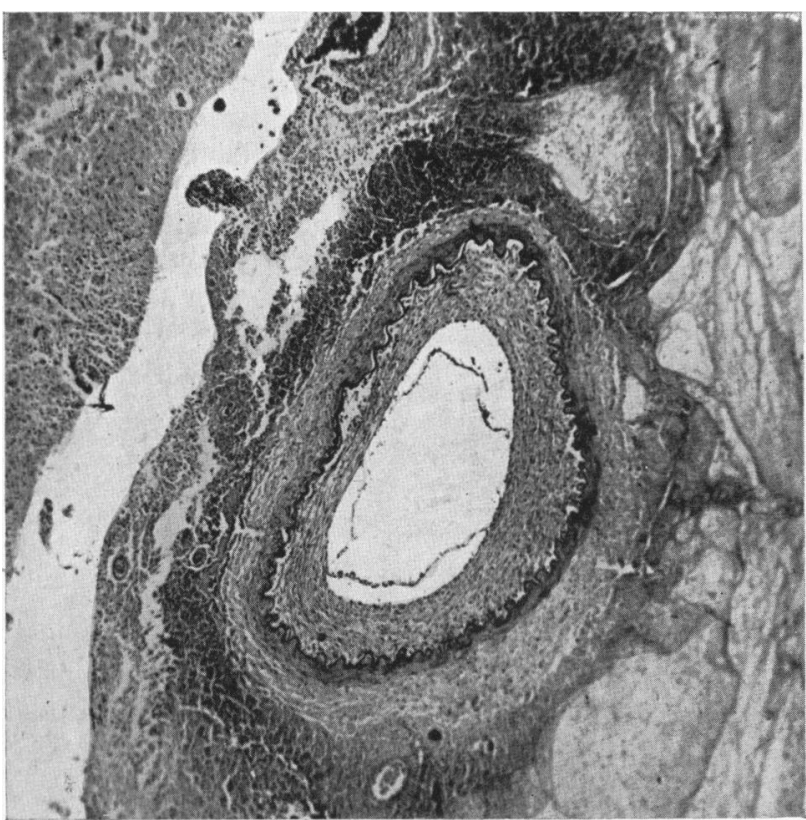

FIG. 3.-Meningeal exudate, necrosis and arteritis. Note: necrosis and infiltrations diminish from without inwards.

It may therefore be assumed that meningitis due to the tubercle bacillus arose in the following manner: blood-borne tubercle bacilli were localized in the meninges or in the juxta meningeal tissues to involve the surrounding meninges and produce a local meningitis. Further extension of this provoked a more marked meningeal exudate and so tuberculous meningitis resulted.

\section{Bacteriology}

The main thing about the bacteriology of tuberculous meningitis is the frequency of the occurrence of the bovine type of bacillus. It is agreed that the bovine bacillus infection in most of these cases has been milk borne. It can thereby be determined how many of such cases might have been prevented from contracting the fatal illness. In this series of twentysix cases of tuberculous meningitis strains of tubercle bacilli were isolated during life from twenty-four. All strains were isolated by culture and subsequently examined as to cultural characteristics and virulence in rabbits. Detail of the results is found in tables 2 and 3.

Technique. Cerebrospinal fluid was centrifugalized. A smear was made and examined microscopically. The deposit was then planted on solid media. Nearly all strains were isolated on Lowenstein's medium; a few were isolated on Dorset's egg medium. After reasonable amount of growth had occurred the strains were subcultured on Dorset's egg media, some containing glycerin. The cultural characteristics were thus obtained. Type differentiation by culture was based on the following findings. The human type gave a more rapid growth on ordinary media; the growth on media con- taining glycerin was even more rapid. In most cases the culture was dry and nodular often resembling breadcrumbs. It was frequently pigmented. The bovine strains grew more slowly on all media and in some cases were inhibited on media containing glycerin. The appearance of the culture was different. It tended to be moist, confluent and did not become pigmented. As soon as the strains had been differentiated by culture small amounts were inoculated intravenously into rabbits. In the case of human strains it was found that they normally survived $0.1 \mathrm{mgm}$. of culture and only developed a few localized lesions. However, bovine strains were more virulent and usually $0.01 \mathrm{mgm}$. killed the rabbit inside six weeks time. This technique is similar to that used by Blacklock (1932).

Results. The cerebrospinal fluids of twentysix cases have been examined microscopically and culturally for the presence of tubercle

TABLE 2

POSITIVE RESULTS

\begin{tabular}{|c|c|c|c|c|c|c|}
\hline No. & Sex & Age & Lesions & $\begin{array}{c}\text { Source } \\
\text { of } \\
\text { infection }\end{array}$ & Direct & Type \\
\hline C3 & F. & 10 & $\begin{array}{l}\text { Pulmonary } \\
\text { miliary } \\
\text { T.M. }\end{array}$ & $\begin{array}{l}\text { Family } \\
\text { history } \\
\text { dênied }\end{array}$ & Pos. & Human \\
\hline $\mathrm{C} 4$ & M. & 14 & $\begin{array}{l}\text { Pulmonary } \\
\text { T.M. }\end{array}$ & Parental & Neg. & Human \\
\hline C5 & M. & 10 & $\begin{array}{l}\text { Pulmonary } \\
\text { T.M. }\end{array}$ & Parental & Neg. & Human \\
\hline C6 & M. & 7 & $\begin{array}{l}\text { ?Pulmonary } \\
\text { hip joint }\end{array}$ & $\begin{array}{c}\text { Parental } \\
\text { ? }\end{array}$ & Neg. & Human \\
\hline $\mathrm{C} 8$ & M. & $1 \frac{1}{4}$ & $\begin{array}{l}\text { ?Abdominal } \\
\text { T.M. }\end{array}$ & Unknown & Pos. & Bovine \\
\hline C9 & M. & 19 & $\begin{array}{l}\text { Pulmonary } \\
\text { T.M. }\end{array}$ & ?Family & Pos. & Human \\
\hline $\mathrm{ClO}$ & M. & $10 \frac{1}{2}$ & $\begin{array}{l}\text { ?Pulmonary } \\
\text { T.M. }\end{array}$ & ?Family & Pos. & Human \\
\hline $\mathrm{C} 11$ & F. & $-\frac{2}{12}$ & $\begin{array}{l}\text { Pulmonary } \\
\text { T.M. }\end{array}$ & Family & Pos. & Human \\
\hline $\mathrm{C} 12$ & F. & $5 \frac{1}{2}$ & $\begin{array}{l}\text { ?Pulmonary } \\
\text { T.M. }\end{array}$ & $?$ & Pos. & Human \\
\hline $\mathrm{C} 13$ & F. & 14 & $\begin{array}{l}\text { Abdominal } \\
\text { miliary } \\
\text { T.M. }\end{array}$ & ?Milk & Pos. & Bovine \\
\hline $\mathrm{Cl} 14$ & M. & 19 & $\begin{array}{l}\text { Pulmonary } \\
\text { T.M. }\end{array}$ & $?$ & Pos. & Human \\
\hline $\mathrm{C} 15$ & M. & $1 \frac{3}{4}$ & $\begin{array}{l}\text { Mesenteric } \\
\text { T.M. }\end{array}$ & Milk & Pos. & Bovine \\
\hline $\mathrm{C} 16$ & F. & 10 & $\begin{array}{l}\text { (Primary) } \\
\text { Abdominal } \\
\text { T.M. }\end{array}$ & $?$ & Pos. & Bovine \\
\hline $\mathrm{Cl}$ & F. & 10 & $\begin{array}{l}\text { Mesenteric } \\
\text { T.M. }\end{array}$ & Milk & Pos. & Bovine \\
\hline $\mathrm{C} 18$ & F. & 19 & $\begin{array}{l}\text { Mesenteric } \\
\text { T.M. }\end{array}$ & $?$ & Pos. & Human \\
\hline C19 & M. & 13 & $\begin{array}{l}\text { ?Primary } \\
\text { T.M. }\end{array}$ & $?$ & Pos. & Bovine \\
\hline $\mathrm{C} 20$ & M. & 7 & $\begin{array}{l}\text { Pulmonary } \\
\text { T.M. }\end{array}$ & $\begin{array}{l}\text { Family } \\
\text { negative }\end{array}$ & Pos. & Human \\
\hline $\mathrm{C} 21$ & F. & 9 & T.M. & ? & Pos. & Bovine \\
\hline
\end{tabular}

T.M. = tuberculous meningitis. 
TABLE 2-continued

\begin{tabular}{|c|c|c|c|c|c|c|}
\hline No. & Sex & Age & Lesions & $\begin{array}{l}\text { Source } \\
\text { of } \\
\text { infection }\end{array}$ & Direct & Type \\
\hline C22 & M. & 7 & $\begin{array}{l}\text { Pulmonary } \\
\text { secondary } \\
\text { mesenteric } \\
\text { T.M. }\end{array}$ & $\begin{array}{l}\text { Family } \\
\text { history }\end{array}$ & Pos. & - \\
\hline $\mathrm{C} 23$ & F. & 6 & $\begin{array}{l}\text { ?Pulmonary } \\
\text { T.M. }\end{array}$ & Family & Pos. & Human \\
\hline C24 & M. & 3 & $\begin{array}{l}\text { Pulmonary } \\
\text { T.M. }\end{array}$ & Family & Neg. & Human \\
\hline C27 & M. & 12 & $\begin{array}{l}\text { Pulmonary } \\
\text { T.M. }\end{array}$ & Family & Pos. & Human \\
\hline C29 & F. & 2 & $\begin{array}{l}\text { Pulmonary } \\
\text { T.M. }\end{array}$ & $?$ & Pos. & Human \\
\hline C30 & F. & 19 & $\begin{array}{l}\text { Pulmonary } \\
\text { T.M. }\end{array}$ & Family & Pos. & Human \\
\hline
\end{tabular}

T.M. = tuberculous meningitis.

TABLE 3

NEGATIVE $\cdot$ RESULTS

\begin{tabular}{|c|c|c|c|c|c|c|}
\hline Case & Sex & Age & Lesions & Direct & Culture & Remarks \\
\hline C31 & $\begin{array}{l}\text { M. } \\
\text { F. }\end{array}$ & - & $\begin{array}{l}\text { Tubercu- } \\
\text { lous } \\
\text { meningitis } \\
\text { T.M. and } \\
\text { primary } \\
\text { unknown }\end{array}$ & $\begin{array}{l}\text { Neg. } \\
\text { Pos. }\end{array}$ & $\begin{array}{l}\text { Neg. } \\
\text { Neg. }\end{array}$ & $\begin{array}{l}\text { Removed } \\
\text { from } \\
\text { hospital } \\
-\end{array}$ \\
\hline
\end{tabular}

bacilli. Analysis of the findings has been made below under the following lines :-

1. The results of the direct microscopical examination of the cerebrospinal fluid.

2. The types of the bacilli isolated and the relation to the ages of the patients and the sex of the patients.

3. The primary complex and the source of infection.

Microscopically. Of the fluids which gave positive cultures tubercle bacilli were seen in twenty. Of the two cases which were negative on culture one was positive on direct examination. The morphology of the organism was not a guide to the type of the bacillus. All the seven fluids which contained bovine bacilli were positive on smear examination.

THE TYPES OF BACILLI. Twenty-four strains were isolated. Of these seven were of the bovine type and the other seventeen the human type. This means a bovine incidence of twenty-nine per cent. When only those under fifteen were included, that is twenty, the incidence was thirty-five per cent. The ages of the patients ranged from two months to nineteen years. All the bovine strains occurred in children of fourteen years old and under. Bovine bacilli were isolated from three males out of thirteen and from four females out of eleven. Of those under fifteen, twenty in all, three bovine strains were obtained from eleven boys and four from nine girls. The total numbers of cases is too small however to justify any significant conclusion on the relationship between the age and sex of the patient and the type of the bacillus.

THE PRIMARY COMPLEX. Only seventeen were sufficiently fully investigated clinically or pathologically to determine the entry route of the tubercle bacilli. Of these primary pulmonary complex occurred in twelve. All the twelve pulmonary cases were associated with bacilli of the human type. Four mesenteric cases were due to bovine type and one to the human bacillus. Entry by the nasopharynx was not proven in any of those cases mentioned above.

THE SOURCE OF INFECTION. Out of ten cases under fifteen years of age and due to the human type a source of infection was found in the family in eight. The source of infection of those bovine cases could not be established on a satisfactory basis because of the interval from the time of the actual infection to the time when the strain was isolated.

\section{SUMMARY OF FINDINGS}

Cerebrospinal fluids 26. $\left.\begin{array}{c}\text { Tubercle bacilli } \\ \text { and types }\end{array}\right\} 24$ strains $\left\{\begin{array}{c}17 \text { human } 13 \text { smear positive } \\ 7 \text { bovine } 7 \text { smear positive }\end{array}\right.$

Two fluids culture negative, 1 smear positive.

Bovine incidence, 0-19 years 29 per cent.; 0-15 years 35 per cent.

Thirteen males-3 bovine.

Eleven females -4 bovine.

Primary thoracic complex, 12 out of 17-all human.

Primary abdominal complex, 5 out of $17-4$ bovine and 1 human.

\section{Discussion}

In comparison 29 per cent. in all ages and 35 per cent. in under fifteens roughly correspond with the findings of other workers. As regards the incidence of types of bacilli, Griffith in 1920 identified two bovine out of twelve strains in a mixed group of lesions (16 per cent.). Later, in 1929, Griffith found 21.8 per cent. bovine bacilli in all ages and of 34 per cent. in those under fourteen. In 1932 Griffith and Munro found it to be 13.3 per cent. Later, in 1934, Griffith in a series of 151 English cases found the percentage of bovine to be 21.8 and from thirty-seven Scottish cases the figure was 40.5. Thus in the later series the incidence in Scotland was much higher than in England. This fact is partly explained by the fact that the majority of them were drawn from the rural districts of Scotland whereas the English cases came from industrial areas. In 1935 MacGregor, Kirkpatrick and Craig found the bovine type in 28 per cent. of cases in Edinburgh and district. These latter findings correspond to the 29 per cent. recorded here for Belfast. Regarding the prevalence in this country of bovine bacilli in between 20 and 40 per cent. of cases findings in other countries are interesting. In Greece (before 1939) and other countries where milk was boiled before use to prevent it going sour only an occasional case of tuberculosis was found to be due to the bovine bacillus. In Toronto since 1916 when pasteurization was made compulsory, Price (1932) was unable to find any bovine tubercle bacilli in 500 cases of 
tuberculous children. This is in direct contrast with the present findings of 29 per cent. in all ages or of 35 per cent. in those under fifteen years of age.

\section{Summary}

Eleven cases of tuberculous meningitis have been examined to determine the pathogenesis of the condition.

From the findings it is concluded that tuberculous meningitis commonly arises as the result of the extension into the subarachnoid space of a focus in the meninges or in the juxta meningeal tissues. This focus is blood borne and may or may not be one of the foci of a miliary tuberculosis.

Cerebrospinal fluids from twenty-six cases of tuberculous meningitis have been examined. Tubercle bacilli have been found microscopically in twenty and strains have been isolated in twenty- four. The incidence of the bovine type of bacilli was 29 per cent. in all ages ( 26 cases) and 35 per cent. in those under fifteen years of age ( 20 cases).

\section{REFERENCES}

Blacklock, J. W. S. (1932). Medical Research Council, Special Report, No. 172.

, and Griffin, M. A. (1935). J. Path. Bact., 40, 489.

Buzzard, F. (1929). Brit. med. J., 1, 839.

Griffith, A. S. (1920). J. Path. Bact., 23, 129. (1929). Ibid., 32, 813. (1934). Lancet, 1, 1382.

- and Munro, W. T. (1932). J. Path. Bact., 35, 271.

Macgregor, A. R., Kirkpatrick, H. J. R., and Craig, W. S. (1934). Lancet, 2, 18.

,-- (1935). Edinb. med. J., 42, 101. , and Alexander, W. A. (1937). Ibid., 44, 561.

- and Green, C. A. (1937). J. Path. Bact., 45, 613.

Price, R. M. (1932). Amer. Rev. Tuberc., 25, 383.

Radmann, C. (1935). Virchows Arch., 295, 563.

Ragins, A. B. (1936). J. Lab. clin. Med., 21, 1217.

Rich, A. R., and McCordock, H. A. (1933). Johns Hopk. Hosp. Bull., 52, 5. 